\title{
Effect of particulates on the dielectric properties and breakdown strength of insulation oil
}

\author{
Ian L. Hosier, Alun S. Vaughan \\ Tony Davis High Voltage Laboratory, \\ University of Southampton, \\ Highfield, Southampton, SO17 1BJ, UK \\ E-mail: ilh@ecs.soton.ac.uk
}

\begin{abstract}
The dielectric properties of dodecylbenzene cable oil containing various concentrations of silica, paper, carbon and copper particles were explored. Dielectric spectroscopy and electrical conductivity measurements revealed a critical concentration above which the dielectric properties were adversely affected by the particles. A reduction in electrical breakdown strength was observed as the particle concentration increased. Carbon was the most deleterious material with only 0.005 wt. \% required to cause a catastrophic reduction in breakdown strength. The results indicate that carbonaceous particulates, which might arise from electrical discharge activity, are particularly detrimental for high voltage plant.
\end{abstract}

Keywords-Particulates; Dodecylbenzene; Dielectric loss; Electrical Conductivity; Electtrical breakdown

\section{INTRODUCTION}

An insulation oil, in conjunction with paper, is used to serve as both dielectric medium and coolant in many items of high voltage plant. Therefore, many laboratory studies have been undertaken on the ageing behaviour of liquid insulation systems usually under accelerated conditions [1]. These studies indicate a gradual deterioration in dielectric properties as well as oxidation and yellowing. Particulate matter may or may not be generated, depending on the type of oil, ageing conditions and the extent of oxidation $[1,2]$.

Despite this, comparatively few studies have been undertaken on the effects of suspended particles on the performance of insulation oils [3-7]. Generally, micron sized particles have a negative effect on breakdown strength and filtration can improve the performance of aged oils [3]. In another study, carbon particles were found to be particularly deleterious [4] whilst in another notable publication [5], nonconductive metal oxide nano-particles improved the breakdown strength whereas electrically conductive metal oxide nano-particles were less beneficial. Recently, the role of particulates in aged dodecylbenzene was studied [6] and, here, the particles were found to be benign. Elsewhere [7], cellulosic particles (i.e. paper) led to bridging and premature breakdown in mineral oil. Aside from thermal ageing, electrical discharge activity can also lead to particle generation; for example, carbonaceous particles which can degrade the dielectric properties $[4,8]$.

In this investigation, dodecylbenzene cable oil was used as a model oil system. Compared to mineral oil, it is free of additives, sulphur and other corrosive compounds and is chemically inert. Particulates were then introduced into the oil in controlled quantities. The effects of particles of varying electrical conductivity from insulating (silica, paper), semiconducting (carbon) to conducting (copper) were explored. Electrical breakdown testing, measurements of dielectric loss and electrical conductivity were used to assess their effects.

\section{EXPERIMENTAL}

Dodecylbenzene [1, 2, 6] was used as supplied. Silica $(5 \mu \mathrm{m})$ and cellulose powder $(20 \mu \mathrm{m})$ were obtained from Sigma Aldrich, copper powder $(5 \mu \mathrm{m})$ was obtained from Goodfellows, whilst carbon black was obtained from Cabot (ELFTEX TP, particle size $<2 \mu \mathrm{m}$ ). After adding the relevant quantity of powder, each oil sample was homogenized for 10 min using a Hielscher UP200S probe sonicator. Solutions of silica and paper were observed to be stable for several hours and carbon for several days, but copper was observed to settle out within an hour. Water content measurements were made using a GR Scientific Aquamax titrator on $1 \mathrm{ml}$ samples.

Dielectric spectroscopy was performed using a cup/plate test cell [6]. After filling the cell, the plates were connected to a Schlumberger SI 1260 impedance gain phase analyzer equipped with a Solartron 1296 dielectric interface. Measurements were made from $0.1 \mathrm{~Hz}$ to $100 \mathrm{kHz}$ using a voltage of $1 \mathrm{~V}_{\mathrm{rms}}$ and averaging over 10 cycles.

Samples for electrical conductivity measurements were placed within a $5 \mathrm{ml}$ test cell composed of a concentric cylinder electrode arrangement with a $2 \mathrm{~mm}$ gap [6]. A computer controlled step voltage program was employed, starting at $100 \mathrm{~V}$, increasing the voltage in $100 \mathrm{~V}$ steps and waiting $10 \mathrm{~s}$ before recording the current. A maximum of $4 \mathrm{kV}(2 \mathrm{kV} / \mathrm{mm})$ was applied to avoid risk of breakdown, which could damage the pico-ammeter (Keithley 6487).

AC breakdown testing was based on the ASTM D1816 standard; the oil was placed into a small volume test cell containing opposing $25 \mathrm{~mm}$ polished chrome steel ball bearings with a $1 \mathrm{~mm}$ gap [6]. An increasing $\mathrm{AC}$ voltage $(50 \mathrm{~Hz}, 50 \mathrm{~V} / \mathrm{s})$ was applied to this arrangement until failure. The oil was stirred and then allowed to settle for $2 \mathrm{~min}$ between each measurement to eliminate air bubbles. Every 5 measurements, the oil and ball bearings were changed. A total of 20 breakdown measurements from each oil system were then analyzed using Weibull statistics. 


\section{RESULTS}

\section{A. Dielectric spectroscopy}

Figs. 1a and $1 \mathrm{~b}$ show the dielectric loss as a function of particle concentration (in wt. \%) for silica and paper
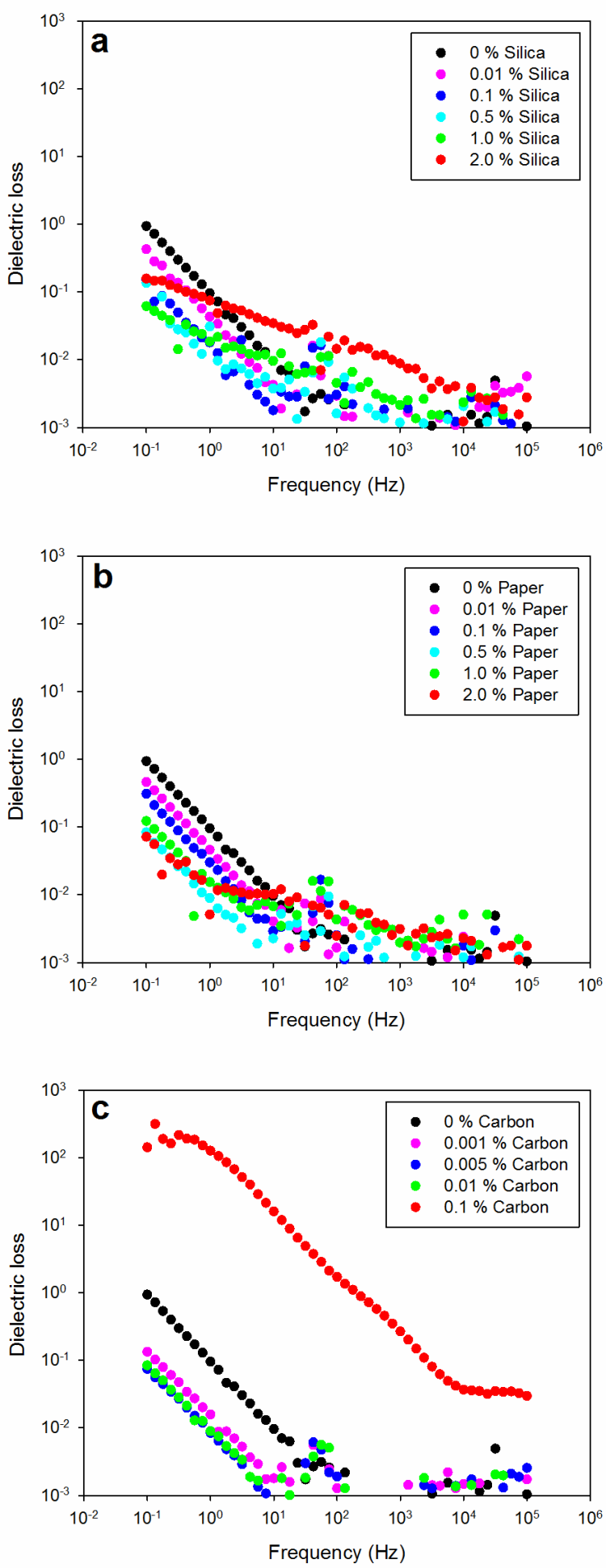

Fig. 1. Dielectric loss of (a) silica solutions (b) paper solutions (c) carbon solutions respectively. With no particles present, the dielectric loss is less than 0.01 at power frequencies $(50 \mathrm{~Hz})$ and $\sim 1.0$ at $0.1 \mathrm{~Hz}$; the gradient of -1 indicates that there is a degree of electrical conductivity associated with the oil. With the addition of up to $1 \%$ of particles, the dielectric loss at power frequencies is gradually reduced, whereas at $2 \%$ loading, the dielectric loss is increased to 0.03 in silica solutions and is around 0.01 in paper solutions. In the paper systems, the corresponding relative permittivity (not shown here for brevity) remains constant at $2.3 \pm 0.1$ but that of the silica systems shows an uplift at low frequencies to 3.1 at $2 \%$ concentration. The results indicate that a $2 \%$ particle loading is starting to have a detrimental effect on the dielectric properties at power frequencies, which is more apparent in the silica systems (Fig. 1a).

Below $0.1 \%$ concentration, carbon solutions (Fig. 1c) show the same type of behaviour as the previous silica and paper solutions showing a gradual reduction in dielectric loss with increasing particle loading. However, at $0.1 \%$ concentration, the dielectric loss takes very high values (320 at $0.1 \mathrm{~Hz}$ ) and is mirrored by a corresponding uplift in relative permittivity $(140$ at $0.1 \mathrm{~Hz})$ which indicates the system is effectively an electrical conductor. Thus, relatively little carbon is required to have a deleterious effect on the dielectric properties. Copper solutions up to $0.5 \%$ concentration behave identically to silica and paper solutions and so data are not shown here. These have a constant relative permittivity of 2.3 \pm 0.1 and higher concentrations were not studied due to particles settling out during testing which led to short circuits in the test cell.

\section{B. Water content}

Measurements of water content are shown in Fig. 2. Samples were left to settle for 1 week and the clear, particle free, oil was then extracted for measurements; the oil was then stirred to include the particles and the measurements were repeated. The results indicate that, following settling and removal of any particles, the water content of the oil is remarkably constant at $45 \pm 10 \mu \mathrm{g} / \mathrm{ml}$ whilst that of stirred solutions, which includes the particles, varies depending on the particle type. Paper carries a significant water content

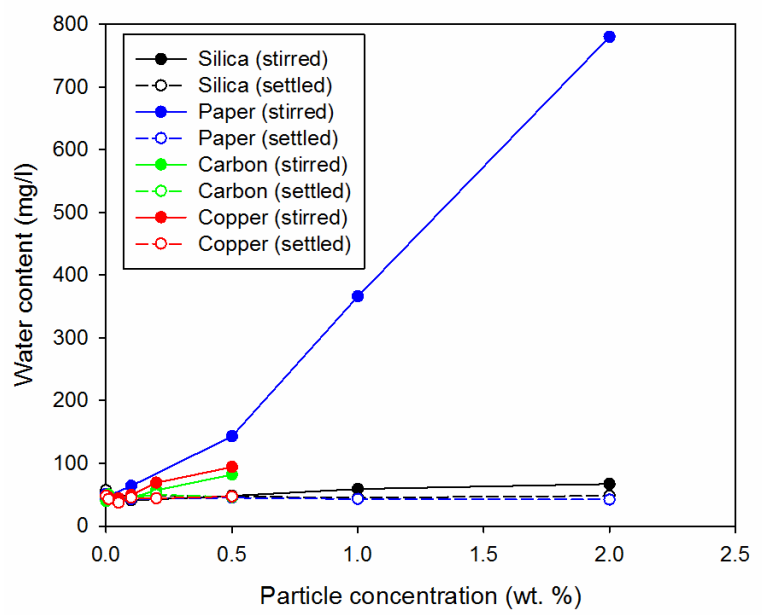

Fig. 2. Water content of settled and stirred solutions 
$\sim 4$ wt. \% (no attempt was made here to dry the paper), but this effect is not evident in the dielectric spectroscopy measurements (see Fig. 1b). Changes in water content also do not explain the deleterious effects of carbon, since the increase in water content at $0.1 \%$ particle concentration is negligible.
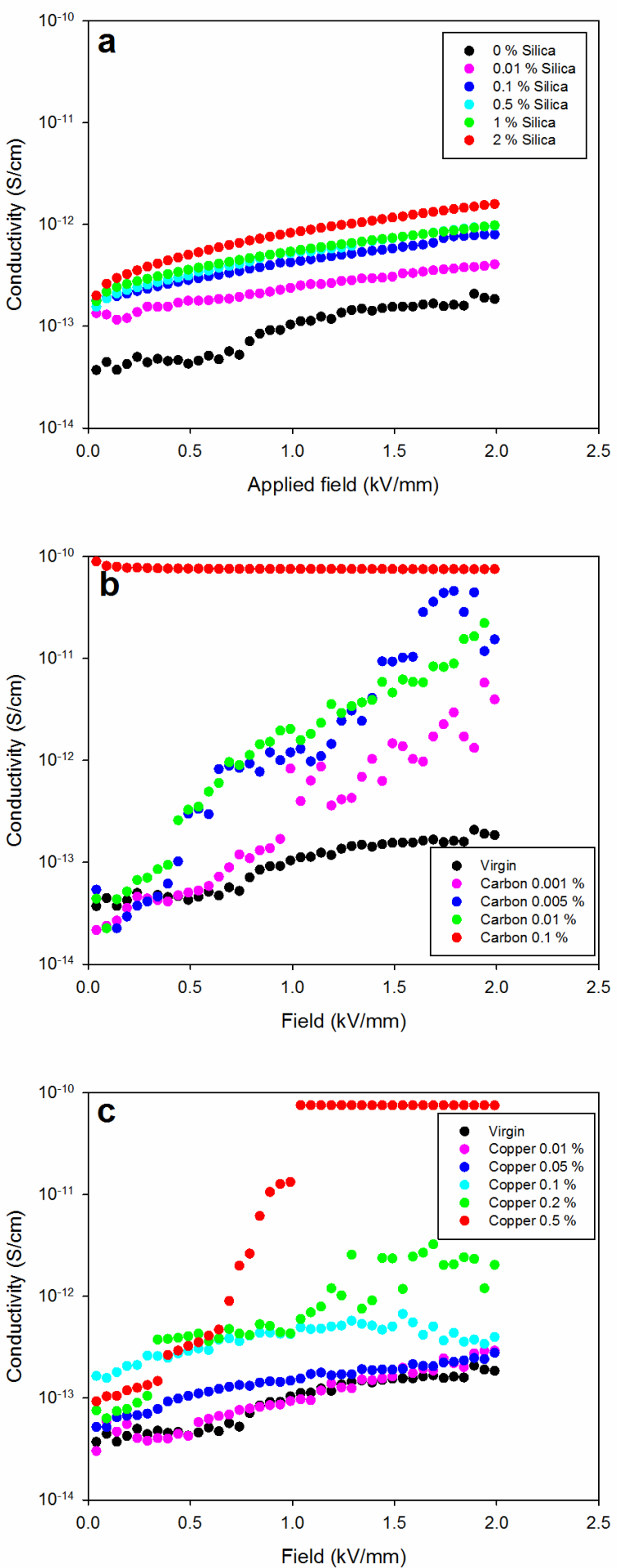

Fig. 3. Electrical conductivity of (a) silica solutions (b) carbon solutions (c) copper solutions.

\section{Electrical conductivity}

Despite a large different in water content, the electrical conductivity results for silica and paper were identical and, hence, only representative data for silica are shown in Fig. 2a. Each system exhibits a gradual increase in conductivity with increasing particle loading, which is not surprising given the rather benign effects of these particles on the dielectric loss behaviour. The behaviour of carbon-containing solutions was, however, very different (Fig. 2b) and shows a strong field dependence and increased electrical conductivity up to $0.01 \%$ concentration at higher applied fields. At $0.1 \%$ concentration the maximum current is measured by the equipment indicating that an electrically conductive solution was then obtained, as indicated by the dielectric spectroscopy data. The behaviour of copper solutions is shown in Fig. 2c; up to $0.2 \%$ concentration a stronger field dependence and increased conductivity was observed. At $0.5 \%$ concentration, the copper particles readily settle out of solution; after some time, this results in a conductive bridge on the bottom insulator of the test cell and, as a result, the maximum allowable current is then recorded.

Clearly the dielectric spectroscopy and the electrical conductivity measurements taken together indicate that silica or paper solutions with $2 \%$ concentration exhibit significantly worse dielectric properties than the oil. Similarly, adding $0.1 \%$ of carbon results in an electrically conductive solution which exhibits a very high dielectric loss. Copper rapidly settles out of solution in less than an hour; this led to problems in some measurements but would be advantageous in plant.

\section{AC breakdown testing}

Results for silica and paper based systems are shown in Fig. 3a and Table I. The breakdown strength $E$ of the oil without any silica or paper is $13 \mathrm{kV} / \mathrm{mm}$ and the data can be split into 3 groups: (a) systems with $0.01 \%$ of silica or paper retain the high breakdown strength and relatively low $\beta$ values associated with the original oil; (b) systems with $0.1 \%$ silica and above have a breakdown strength around $9 \mathrm{kV} / \mathrm{mm}$ and a higher $\beta$ value; (c) systems with $0.1 \%$ paper or more have a breakdown strength of around $6 \mathrm{kV} / \mathrm{mm}$ and an increased $\beta$ value. Higher $\beta$ values and lowered breakdown strengths were also found in aged oils [6] and similarly, here, breakdown took place through a "bridge" [7]. Fig. 3b shows Weibull plots for carbon and copper systems and Table II contains the associated numerical data. In this case the data fall into 2 groups; (a) systems containing $0.001 \%$ carbon and up to $0.05 \%$ copper retain the high breakdown strength and low $\beta$ value associated

TABLE I. BREAKDOWN DATA FOR SILICA AND PAPER SOLUTIONS

\begin{tabular}{|l|l|l|l|l|}
\hline \multirow{2}{*}{ Concentration } & \multicolumn{2}{|c|}{ Silica } & \multicolumn{2}{c|}{ Paper } \\
\cline { 2 - 5 } & \multicolumn{1}{|c|}{$\boldsymbol{E}(\boldsymbol{k V} / \mathbf{m m})$} & $\boldsymbol{B}$ & $\boldsymbol{E}(\boldsymbol{k V} / \mathbf{m m})$ & $\boldsymbol{\beta}$ \\
\hline 0 & 13.0 & 2.8 & & \\
\hline 0.01 & 13.5 & 3.9 & 10.0 & 3.0 \\
\hline 0.1 & 10.3 & 11.0 & 5.6 & 4.9 \\
\hline 0.5 & 8.6 & 10.6 & 5.7 & 9.1 \\
\hline 1.0 & 8.3 & 7.8 & 5.9 & 11.8 \\
\hline
\end{tabular}


with the original oil (b) higher concentrations of particles lead to lower breakdown strengths and a higher $\beta$ value. Again, breakdown was observed to take place through a "bridge".
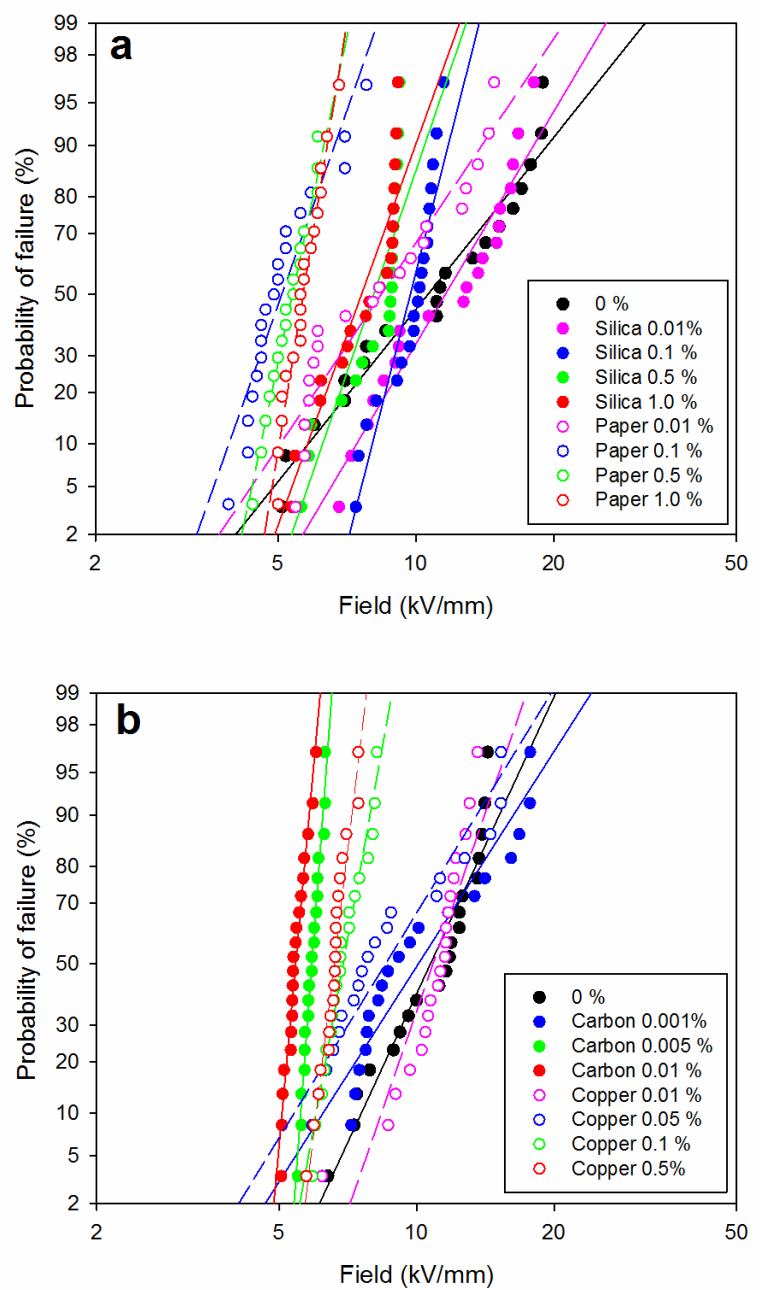

Fig. 4. Weibull plots from (a) silica and paper systems (b) carbon and copper systems

TABLE II. BREAKDOWN DATA FOR CARBON AND COPPER SOLUTIONS

\begin{tabular}{|l|l|l|l|l|}
\hline \multirow{2}{*}{ Concentration } & \multicolumn{2}{|c|}{ Carbon } & \multicolumn{2}{c|}{ Copper } \\
\cline { 2 - 5 } & $\boldsymbol{E}(\mathrm{kV} / \mathrm{mm})$ & $\boldsymbol{B}$ & $\boldsymbol{E}(\mathrm{kV} / \mathrm{mm})$ & $\boldsymbol{\beta}$ \\
\hline 0 & 12.0 & 5.5 & & \\
\hline 0.001 & 12.0 & 3.0 & & \\
\hline 0.005 & 6.0 & 26.5 & & \\
\hline 0.01 & 5.6 & 20.1 & 17.5 & 8.6 \\
\hline 0.05 & & & 10.1 & 3.1 \\
\hline 0.1 & & & 7.3 & 10.6 \\
\hline 0.5 & & & 6.8 & 16.1 \\
\hline
\end{tabular}

\section{CONCLUSIONS}

Dodecylbenzene was mixed with various concentrations of silica, paper, carbon and copper and its dielectric performance was measured as a function of particle concentration.

Electrically insulating particles, such as silica and paper, led only to moderate increases in electrical conductivity and increased dielectric loss was only observed at the highest concentration $(2 \%)$. In breakdown tests, concentrations of $0.1 \%$ or more led to reduced breakdown strength.

Semi-conducting particles, such as carbon, led to significantly increased conductivity, such that at $0.1 \%$ concentration an electrically conducting fluid was obtained. Breakdown tests indicated detrimental effects at very low particle concentrations $(0.005 \%)$.

Conducting particles, such as copper, were more benign, however they settled out quickly leading to problems with some measurements. Their solutions exhibited reduced breakdown performance at concentrations of $0.1 \%$ or more.

These results show, in agreement with other studies [4, 8], that carbonaceous particles are particularly hazardous in high voltage plant. In contrast, non-conducting particles tend to be more benign as suggested elsewhere $[5,6]$.

\section{ACKNOWLEDGMENT}

We would like to thank Junxuan Chen and Sandra Ucheolowu for carrying out the electrical breakdown measurements.

\section{REFERENCES}

[1] I. L. Hosier, A. S. Vaughan, S. J. Sutton, F. J. Davis, "Chemical, Physical and Electrical Properties of Aged Dodecylbenzene: Thermal Ageing of Mixed Isomers in Air", IEEE Trans. Diel. Electr. Insul., 14, pp. 1113-1124, 2007

[2] I. L. Hosier, A. S. Vaughan. S. J. Sutton, J. Cooper, F. J. Davis, "Chemical, physical and electrical properties of aged dodecylbenzene 3: Thermal ageing of mixed isomers in nitrogen and under sealed conditions", IEEE Trans. Diel. Electr. Insul., 15, pp. 1056-1064, 2008.

[3] X. Wang and Z.D. Wang, "Particle Effect on Breakdown Voltage of Mineral and Ester Based Transformer Oils", In 2008 Ann. Rep. Conf. on Electr. Insul. Diel. Phen., pp. 386-390 (Quebec City, Canada, $29^{\text {th }}-29^{\text {th }}$ October 2008)

[4] M. Krins, H. Borsi, and E. Gockenbach, "Influence of Carbon Particles on the Breakdown Voltage of Transformer Oil", In Proc. 12 $2^{\text {th }}$ Intern. Conf. Cond. Breakd. Diel. Liq., pp. 296-299 (Rome, Italy, $15^{\text {th }}-19^{\text {th }}$ July 1996).

[5] Y. Lv, W. Wang, K. Ma, S. Zhang, Y. Zhou, C. Li, Q. Wang, "Nanoparticle Effect on Dielectric Breakdown Strength of Transformer Oil-Based Nanofluids", In 2013 Ann. Rep. Conf. on Electr. Insul. Diel. Phen., pp. 680 - 682 (Chenzhen, China, $20^{\text {th }}-23^{\text {rd }}$ October 2013).

[6] I. L. Hosier, J. E. A. Koilraj and A. S. Vaughan, "Effect of Aging on the Physical, Chemical and Dielectric Properties of Dodecylbenzene", IEEE Trans. Diel. Electr. Insul., 23, pp. 3389-3396, 2016.

[7] S. Mahmud, G. Chen, I. O. Golosnoy, G. Wilson, P. Jarman, "Experimental Studies of influence of DC and AC Electric Fields on Bridging in Contaminated Transformer Oil", IEEE Trans. Diel.Electr. Insul., 22, pp. 152 - 160, 2015.

[8] I. L. Hosier, H. Ma and A. S. Vaughan, "Effect of electrical and thermal ageing on the breakdown strength of silicone oil", , In Proc. 18th IEEE Intern. Conf. Diel. Liq., Paper 160 (Bled, Slovenia, 30th June - 3rd July 2014). 